\title{
Coronary Sinus Atrial Septal Defect without Persistent Left Superior Vena Cava: Single Vessel Coronary Artery Disease, Surgically Managed - A Rarest Case Report
}

Sujit Kumar Mohanty*, Sunil Kumar Satpathy, Farooqi, Rama Krishna, Jaydeep Trivedi,Ravi kumar cardiovascular thoracic surgery, Apollo hospitals Visakhapatnam, India.

*Corresponding Author: Sujit Kumar Mohanty, cardiovascular thoracic surgery, Apollo hospitals Visakhapatnam, India Received date: July 30 2020; Accepted date: August 29, 2020; Published date: September 05, 2020

Citation: Sujit Kumar Mohanty. (2020) Coronary Sinus Atrial Septal Defect without Persistent Left Superior Vena Cava: Single Vessel Coronary Artery Disease, Surgically Managed - A Rarest Case Report. International Journal of Clinical Case Reports and Reviews. 3(3); DOI: 10.31579/26904861/037

Copyright: (C) 2020 Sujit Kumar Mohanty, This is an open-access article distributed under the terms of the Creative Commons Attribution License, which permits unrestricted use, distribution, and reproduction in any medium, provided the original author and source are credited.
Abstract:
Coronary sinus defect is a spectrum of cardiac anomalies in which part or all of the common wall between the coronary sinus and left atrium is absent.By morphology, it may present completely unroofed coronary sinus or completely unroofed coronary sinus without persistent left superior vena cava also it may present like partially unroofed midportion or terminal portion of coronary sinus. Depending upon the morphology cyanosis is mild to severe.
We are reporting a case of partial coronary sinus defect in an adult female patient with coronary artery disease.
Keywords: coronary sinus; coronary artery disease; left superior vena

\section{Introduction}

True understanding of the morphology of the syndrome awarded the classic paper by raghib, Edwards and colleagues in 1965. The descriptive phrase unrefined coronary sinus was first used by Helseth and Peter in 1974. Unroofed coronary sinus has it meet common major association cardiac anomaly in the atrioventricular septal defect.

The partially unroofed midportion of coronary sinus also called the biatrial opening of the coronary sinus or coronary sinus-to-left atrial window or fenestration. Diagnosis of the unroofed coronary sinus in made by echocardiography and confirmed at operation.

The degree of cyanosis or desaturation depends on the presence of persistent left superior vena cava and extend of unroofing of the coronary sinus.

\section{Case Report}

A 60 years old female presented with moderate effort intolerance, pulse oximeter saturation of $96 \%$ moderate cardiomegaly, a wide, fixed split second heart sound and systolic outflow murmur. a chest radiography showed Cardio megaly, dilated pulmonary arteries, and plethora . Electrocardiogram showed sinus rhythm with normal cardiac axis and RSR pattern in V1.

Echocardiography revealed an enlarged ostium of the coronary sinus, which was shunting left to right there was an unroofing of the terminal portion of the coronary sinus, where the left atrial blood entered the dilated coronary sinus. The right atrium and the right ventricle were dilated without evidence of pulmonary arterial hypotension.
We did also coronary angiography which was showing left anterior descending coronary artery normal. Left circumflex normal but rt. Coronary artery has $90 \%$ lesion.

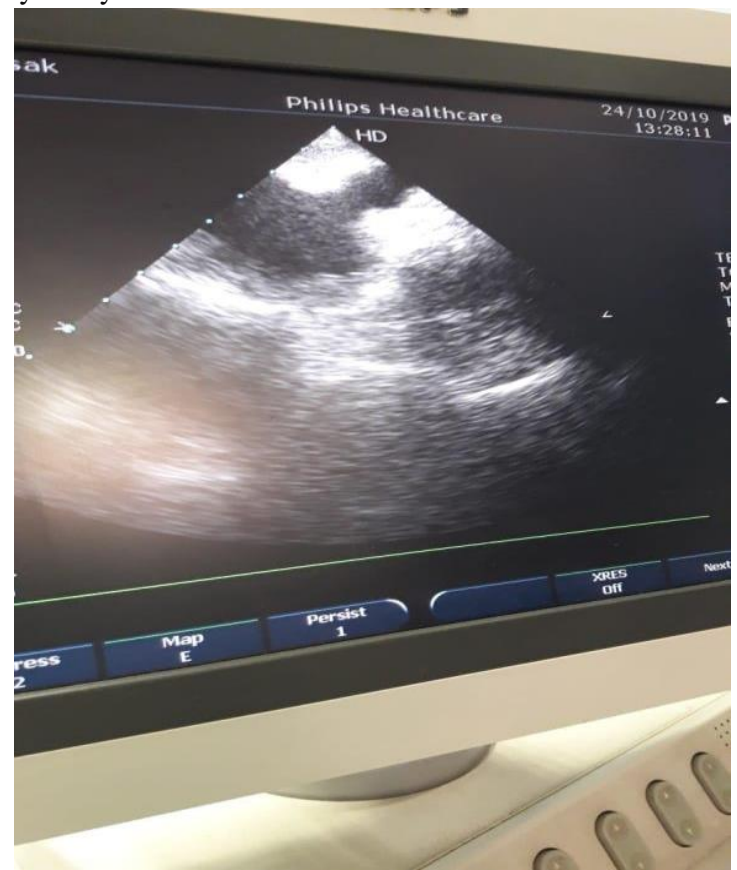

Fig; 1 - echo view shows dilated right atrium and right ventricle, dilated coronary sinus and the terminal unroofing of the coronary sinus. 
So after taking to operation theatre and drapping over, midsternotomy done.pericardiotomy and stay suture taken pericardium also harvested simultaneously saphenous vein harvested from leg then after heparinization. Aortic, SVC, IVC cannulation done, pt was put on cardiopulmonary bypass. We grafted rt posterior descending artery with reversed saphenous vein graft followed by proximal to aorta on pump beating heart we put antegrade cardioplegic canula, temperature drift to 32 degrees centigrade.

SVC, IVC snugged with umblical tape. Then cross clamp on cardioplegic given heart arrested RA open, a dilated coronary sinus seen. then we open interatrial septum, there is two separate opening in the mid terminal part of coronary sinus, no left svc found we also confirm with by given cardioplegia through antigrade, blood coming from these two openings. Both the opening we closed with separate e pericardial patch (as shown in fig $2 \&$ fig 3 ) after that it is reconfirmed.

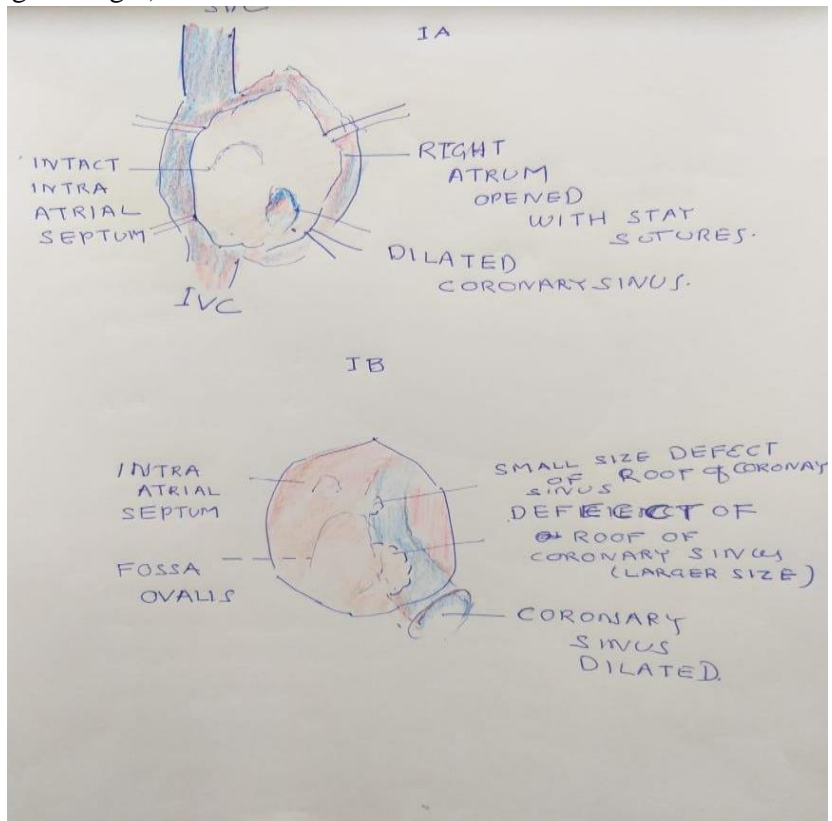

Figure-2 Showing Schematic diagram of unroofed coronary sinus.

There is no leakage to left atrium after giving cardioplegia, interatrial septum closed directly then. Right atrium closed in two layers. rewarming done umblical tape desnugged after deairing cross clamp taken out heart beating started blood pressure and heart rate came to normal with minimal inotrope supports gradual weaning from cardio pulmonary bypass, we also did transesophgeal echocardiography (TEE) showing no left to right shunt through coronary sinus..

Defects located posteroinferior to the oval fossa are extremely rare interatrial communications and are often associated with PLSVC. This is caused by a defect in the embryonic left -atrio venous fold which forms a common wall between coronary sinus and the left atrium. they may be unrecognizable, when they occur in any form of atrioventricular septal defect .complete unroofing of coronary sinus is described as type 1 or 2 in the presence or absence of PLSVC, respectively partial unroofing is described as type 3 or 4 when the mid or terminal portion of the coronary sinus is involved .our patients is, an example type 3, 4 defect then as outline decannulation done. And after Protamin given and hemostasis maintained. Sternum closed with steel wire, wound closed in layer, patient shifted to ICU in stable condition, patient did well and discharge from hospital on $11^{\text {th }}$ post-operative day.

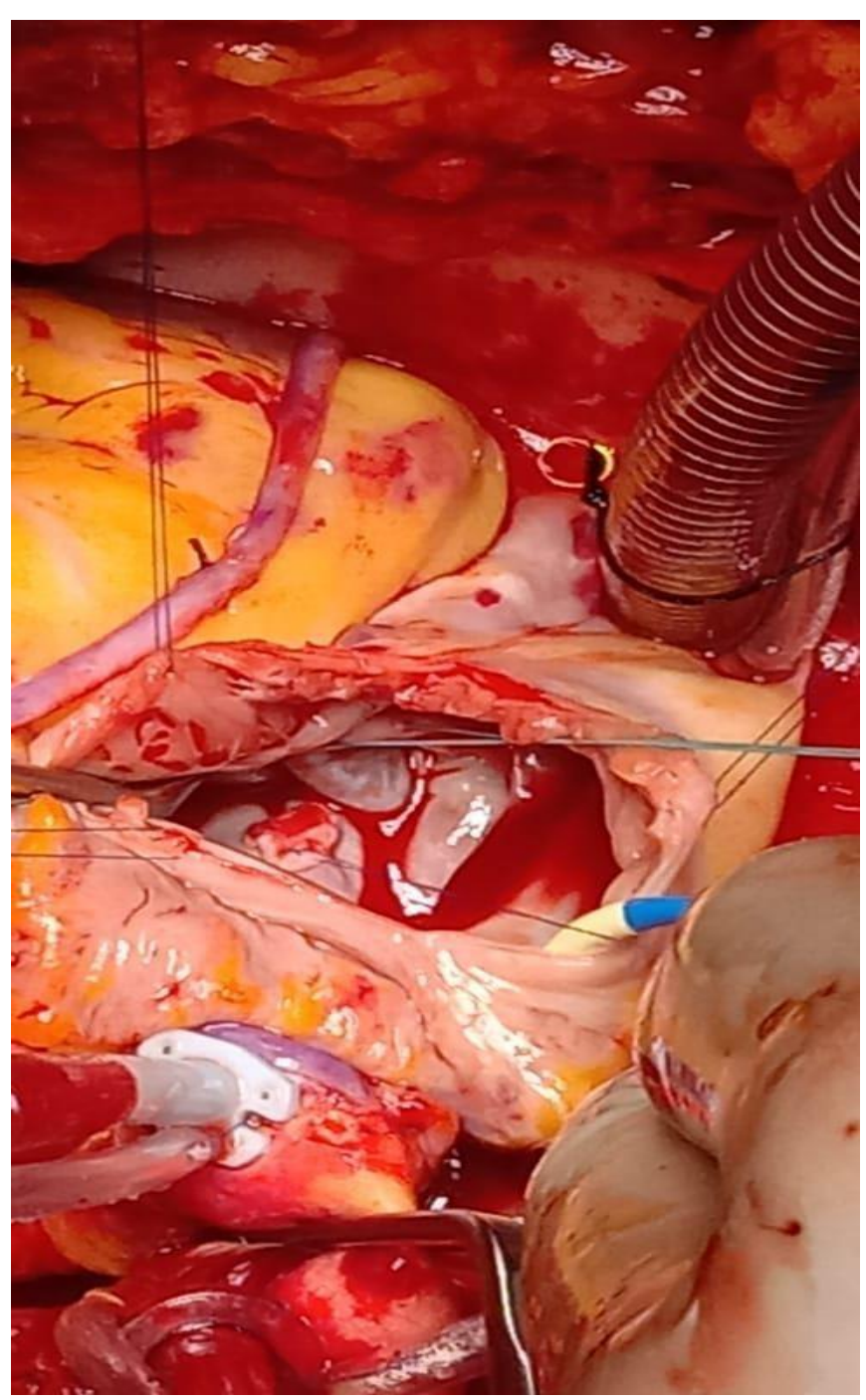

Figure-3 Showing surgical view after opening right atrium also showing grafting of reverse saphenous vein graft to RT coronary art (RSVG)

Deceleration Of Patient Consent - the authors certify that they have obtained all appropriate patient consent forms in the form the patients has/ have given his /her / their consent for his /her /their images and other clinical information to be reported in the journal. The patient understand that their names and initials will not be published and due efforts will be made to conceal their identity, but anonymity cannot be guaranteed.

\section{Financial Support and Sponsorship - nil}

\section{Conflicts Of Interest - There are no conflicts of interest.}

\section{Reference-}

1. Samuel W, Robert E M, Atrial Septal Defect, unroofed coronary sinus.

2. Foster ED, Baeza OR, farina MF, shaher RM. (1978) atrial septal defect associated with drainage of left superior vana cava to left atrium and absence of the coronary sinus .j. thorac cardiovasc surg . 76:718 -720.

3. Raghid G, Rutteenberg HD, Anderson RC, amplatz K, adams P, 
$\mathrm{Jr}$, Edwards JE, et al.

(1965) termination of left superior vena cava in left atrium, atrial septal defect, and absence of coronary sinus; a development complex .circulation. 31:906 -918.

4. Kirklin JW, barratt boyes BG. (1986) unroofed coronary sinus syndrome, in: kirklin JW, barrat -boyes BG, editor's .cardiac surgery . $1^{\text {st }}$ New York: wiley and sons.pp.533- 540.

5. Del bene MR, barletta G. (1997) echocardiographic diagnosis of coronary sinus type atrial septal defect .A case report .Minerva Cardioangiol .45:315-318.
6. Takahashi H, sakamoto $\mathrm{T}$, amano $\mathrm{K}$, Hada $\mathrm{Y}$,S erizawa $\mathrm{T}$, tomaru T,et al . (1985) coronary sinus type atrial septal defect diagnosis by two -dimensional color doppler echocardiography: a case report J.cardiogr .15:1283-1291.

7. De la espriella -juan $\mathrm{R}$, paya -serrano $\mathrm{R}$,cubillos - arango A,bochard -villanueva B,sanchez-alvarez s ,morell -cabedo S,et al. (2017) coronary sinus atrial septal defect in a 65- years -old woman : diagnosis by two -and three -dimensional ecocardiography .rev port cardiol .36 :67-68.
This work is licensed under Creative

Commons Attribution 4.0 License

To Submit Your Article Click Here: Submit Article

DOI: $10.31579 / 2690-4861 / 037$
Ready to submit your research? Choose Auctores and benefit from:

* fast, convenient online submission

* rigorous peer review by experienced research in your field

* rapid publication on acceptance

* authors retain copyrights

* unique DOI for all articles

* immediate, unrestricted online access

At Auctores, research is always in progress.

Learn more www.auctoresonline.org/journals/international-journal-ofclinical-case-reports-and-reviews 